Conclusions and Recommendations, are particularly interesting in view of the controversies aroused by the Warnock Report. Many of the recommendations contained here are similar to Warnock's (for example, concerning the legitimacy of AID children, the need for a licensing authority to supervise the work of AID and IVF centres, etc), but others are at odds with the corresponding Warnock recommendations. In general, the authors place higher value on the family as an institution than did the Warnock Committee and display a much livelier awareness of the possible social dangers of the new techniques.

One weakness of the book is that since its authors are approaching these topics from the standpoint of social scientists, their recommendations for legislative action - which surely must be based on properly ethical considerations, not merely sociological ones - seem devoid of any satisfactory rational support. For example, they concede that experimentation on human embryos is an objectionable practice, since 'the material acting as the subject of the experimentation is a human being at the beginning of its individual development' ( $p$ 178); but the practical recommendation which they make concerning this practice is disappointingly feeble:

'The value placed upon human life is so great that experimentation upon human embryos should only be undertaken if it can be shown to be in the public interest.' (p 179.)

But if the embryo is really a human being then surely experimentation upon it is morally wrong regardless of whether it is in the public interest or not? Here, I suspect, the authors' concentration on sociological issues leads them to overlook the crucial moral issues at stake and unthinkingly to adopt a fashionable but extremely dubious consequentialism on this and some other important issues. But as a social investigation this book is very worthwhile and deserves to be widely read. It is also refreshingly free from the pretentious jargon which sometimes disfigures studies of this sort.

F J FITZPATRICK Education and Research Officer, The Linacre Centre for the Study of the Ethics of Health Care, London

\section{Ethics and the Limits of Philosophy}

Bernard Williams, 230 pages, London, $£ 10.95$, Fontana and William Collins, 1985.

Moral philosophy can be relevant to a medical readership although it does not deal specifically with the problems encountered in medicine and nursing. This is because moral philosophers can offer discussions of concepts such as harm, consent, quality of life, paternalism and many others which encapsulate the moral problems of medical and nursing practice. But there are also treatises on moral philosophy which, while doubtless admired by professional philosophers, seem to the layman to be remote from the moral problems of ordinary life and professional practice. This book is in the latter category rather than the former. It is simply not true to say, as the cover does say, that it does not demand a philosophical training to follow'. The difficulty is not that technical words are used but rather that the argument proceeds at a high level of abstraction from real-life moral problems. It offers a theory about other theories.

The theory it offers has two main strands in it. The first is that the Socratic question, 'How should one live?' is an ethical question as distinct from merely a moral one, and that we would all do better to concentrate on the 'ethical' and drop the 'moral'. The trouble with the working out of this theme however is that the sphere of the ethical is left vague, and morality with its obligations, which we would be better without (p 174), is liable to reappear disguised as the ethical with its 'shoulds'. The second strand is that 'The resources of most modern moral philosophy are not well adjusted to the modern world' (p 197). The case for this is not really made out, and readers of this journal will appreciate that within its pages at least there is some moral philosophy which does sometimes succeed in adjusting to the moral problems of the modern world. Nevertheless, there are many excellent discussions in the book of such matters as objectivity and relativism (chapters 8 and 9). The general conclusions are negative, although sometimes this stems from a humility about what can be achieved by moral philosophy, and an admiration for what has been achieved by science. But the pessimism about the relevance of moral philosophy to the modern world was more apt in the period 1950-70. Nowadays many philosophers have tried to apply theif analytical skills to problems in medicine, politics, the environment an so on. Indeed, Williams himself was entirely appropriate as the Chairman of the Government Committee on Obscenity and Film Censorship, and of course Mary Warnock chaired another famous committee. Both of these were attempts to adjust moral philosophy to the modern world. No doubt there is still room for improvement in moral philosophy, but the improvement does not require a distinction between the ethical and the moral or another conception of rationality, but rather some homework on what scientists, doctors, economists etc actually say.

R S DOWNIE Professor of Moral Philosophy, Glasgow University

\section{Cecily Pembroke \\ Would the person who sent us a case study about Cecily Pembroke please write to the Editor. It arrived without any covering letter and our detective work is not up to the task of tracing its author(s).}

Editor 